\title{
Selective Inhibition of Hypoxia-Inducible Factor (HIF) Prolyl-Hydroxylase 1 Mediates Neuroprotection against Normoxic Oxidative Death via HIF- and CREB-Independent Pathways
}

\author{
Ambreena Siddiq, ${ }^{1,2}$ Leila R. Aminova, ${ }^{3}$ Carol M. Troy, ${ }^{4}$ Kyungsun Suh, ${ }^{1,2}$ Zachary Messer, ${ }^{1}$ Gregg L. Semenza, ${ }^{5}$ and \\ Rajiv R. Ratan ${ }^{1,2}$ \\ ${ }^{1}$ Department of Neurosciences, Burke Medical Research Institute, White Plains, New York 10605, ${ }^{2}$ Department of Neurosciences, Weill Medical College of \\ Cornell University, New York, New York 10065, 32Department of Microbiology, University of Illinois at Urbana-Champaign, Urbana, Illinois 61801, \\ ${ }^{4}$ Department of Pathology, Columbia University College of Physicians and Surgeons, New York, New York 10032, and ${ }^{5}$ Institute for Cell Engineering and \\ Department of Genetics, Johns Hopkins University School of Medicine, Baltimore, Maryland 21205
}

Oxidative stress contributes to tissue injury in conditions ranging from cardiovascular disease to stroke, spinal cord injury, neurodegeneration, and perhaps even aging. Yet the efficacy of antioxidants in human disease has been mixed at best. We need a better understanding of the mechanisms by which established antioxidants combat oxidative stress. Iron chelators are well established inhibitors of oxidative death in both neural and non-neural tissues, but their precise mechanism of action remains elusive. The prevailing but not completely substantiated view is that iron chelators prevent oxidative injury by suppressing Fenton chemistry and the formation of highly reactive hydroxyl radicals. Here, we show that iron chelation protects, rather unexpectedly, by inhibiting the hypoxia-inducible factor prolyl 4-hydroxylase isoform 1 (PHD1), an iron and 2-oxoglutarate-dependent dioxygenase. PHD1 and its isoforms 2 and 3 are best known for stabilizing transcriptional regulators involved in hypoxic adaptation, such as HIF-1 $\alpha$ and cAMP response element-binding protein (CREB). Yet we find that global hypoxia-inducible factor (HIF)-PHD inhibition protects neurons even when HIF-1 $\alpha$ and CREB are directly suppressed. Moreover, two global HIF-PHD inhibitors continued to be neuroprotective even in the presence of diminished HIF-2 $\alpha$ levels, which itself increases neuronal susceptibility to oxidative stress. Finally, RNA interference to PHD1 but not isoforms PHD2 or PHD3 prevents oxidative death, independent of HIF activation. Together, these studies suggest that iron chelators can prevent normoxic oxidative neuronal death through selective inhibition of PHD1 but independent of HIF-1 $\alpha$ and CREB; and that HIF- $2 \alpha$, not HIF-1 $\alpha$, regulates susceptibility to normoxic oxidative neuronal death.

\section{Introduction}

Oxidative stress contributes to the pathogenesis of a number of neurological conditions (Hayashi, 2009; Krasnova and Cadet, 2009; Levy et al., 2009; Liot et al., 2009; Maccioni et al., 2009; Terni et al., 2009; Trimmer and Bennett, 2009). Occurring when the production of reactive oxygen species overwhelms a cell's detoxification capacity, oxidative stress can damage DNA, deplete ATP, and induce cell death (Hwang et al., 2009; Shokolenko et al., 2009; Unnikrishnan et al., 2009; Visconti and Grieco, 2009). Most enzymes that produce reactive oxygen species contain a

Received April 14, 2009; revised May 22, 2009; accepted June 1, 2009.

This study was financially supported by New York State Department of Health Center of Research Excellence in Spinal Cord Injury (Grant C019772 to R.R.R.), Adelson Foundation, and National Institutes of Health R01 (Grants NS 40591, NS 46239, and NS37060 to R.R.R.). We are thankful to Rachel Speer, Xia Li, Hsin-Hwa Lee, Dr. Wilfredo Mellado, Dr. Renee Haskew-Layton, and Dr. Sama Sleiman for their help and support with this project. We thank Vicki Brandt for thoughtful editorial assistance and Dr. John Cave for help with figures.

Correspondence should be addressed to either of the following: Dr. Ambreena Siddiq or Dr. Rajiv R. Ratan, Burke Medical Research Institute, 785 Mamaroneck Avenue, White Plains, NY 10605, E-mail: ams2028@med.cornell.edu or rrr2001@med.cornell.edu.

D01:10.1523/JNEUROSCI.1779-09.2009

Copyright $\odot 2009$ Society for Neuroscience $\quad$ 0270-6474/09/298828-11\$15.00/0 metal such as iron or copper; iron in particular is an essential element in propagating neuronal injury (Dröge and Schipper, 2007). Iron chelation can prevent oxidative death in vitro, and low molecular weight or protein chelators of iron have been found to prevent injury in a host of neurological conditions in rodents as well as in a small pilot clinical trial in Alzheimer disease in humans (Lee et al., 2005; Bush, 2008).

Yet there has been no convincing evidence pointing to a single target that could mediate the salutary effects of iron chelation. We initially proposed that iron chelators prevent normoxic oxidative death by stabilizing the transcription factor hypoxia-inducible factor-1 (HIF-1) and thereby increasing transcription of its downstream target genes such as erythropoietin (Epo), glycolytic enzymes, and vascular endothelial growth factor (VEGF) (Zaman et al., 1999; Li et al., 2008). HIF levels are regulated by the activity of a group of enzymes called HIF-prolyl 4-hydroxylases (HIFPHDs) that require iron, oxygen and 2-oxoglutarate (2-OG) to hydroxylate proline residues pro-564 or pro-402 (amino acid positions designated in humans) in the HIF- $1 \alpha$ molecule (Kaelin and Ratcliffe, 2008). Hydroxylation of HIF-1 allows it to bind to 

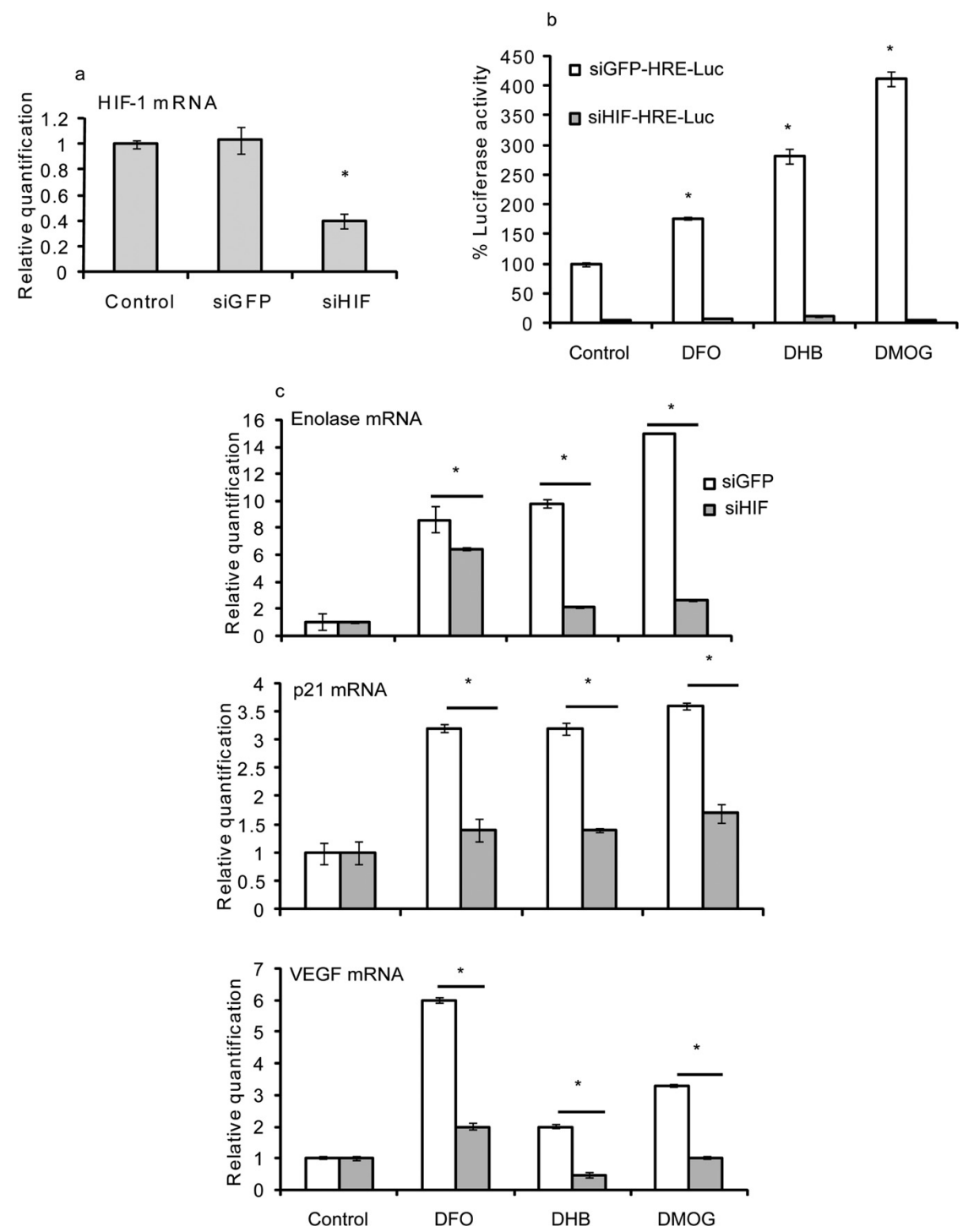

Figure 1. Validation of shRNA against HIF-1 $\alpha . \boldsymbol{a}$, HT22 cells were infected with a retrovirus containing shGFP (siGFP) or shHIF-1 $\alpha$ (siHIF-1) and selected for 1 week using puromycin. Real-time PCR analysis was performed for relative quantification of HIF-1 $\alpha$ mRNA levels. $\boldsymbol{b}$, Percentage luciferase activity after siHIF or siGFP cells were transiently transfected with HRE-luciferase reporter and treated with DF0, DHB, or DMOG. c, Relative quantification of HIF-1 downstream genes enolase 1 (top), p21 (middle), and VEGF (bottom) in siHIF-1 and siGFP overexpressing cells treated with DFO (100 $\mu \mathrm{M})$, DHB $(10 \mu \mathrm{M})$, or DMOG (2.5 mM). Graph depicts comparison to nontreated control \pm SD calculated from three separate experiments for each group. ${ }^{*} p \leq 0.05$ by ANOVA and Student-Newman-Keuls tests.

the Von Hippel Lindau (pVHL)-E3 ubiquitin ligase complex and undergo proteasomal degradation. Iron chelators or structural analogues of 2-OG inhibit the activity of HIF-PHDs and therefore stabilize HIF (Bruick and McKnight, 2001; Ivan et al., 2001; Jaakkola et al., 2001). Our previous work implicated the HIFPHDs in protection from oxidative death by iron chelation, but left two important questions unanswered (Aminova et al., 2005, 2008; Siddiq et al., 2005). Do one or more isoforms of the HIFPHDs need to be inhibited to prevent normoxic oxidative death? And second, is HIF necessary for protection by HIF-PHD inhibition?

There are three different isoforms of PHDs present in the brain: HIF-PHD1, -PHD2, and -PHD3 (Epstein et al., 2001). Small molecules that target all three prevent neuronal death in vitro and in vivo (Siddiq et al., 2005). Although the three isoforms share homology in the C-terminal catalytic domain, they have significant differences in their N-terminal sequences. PHD1, 2, and 3 also differ in their expression patterns, tissue distribution, subcellular localization, and their ability to hydroxylate HIF-1 (Siddiq et al., 2007, 2008). Furthermore, isoform-specific patterns of PHD induction by hypoxia/ischemia alter the abundance and therefore the relative contribution of each isoform toward HIF regulation. These distinct characteristics of the three isoforms of PHDs suggest that the protective effects of PHD inhibition might involve mechanisms that are independent of HIF-1, with each isoform regulating distinct pathways that contribute toward the overall scheme of neuroprotection.

We investigated the role of HIF isoforms and cAMP response elementbinding protein (CREB) in neuroprotection induced by HIF-PHD inhibition. Our findings suggest that the knockdown of isoform PHD1 prevents oxidative death via mechanisms independent of HIF-1, HIF-2, or CREB. Moreover, steady state levels of HIF-2 under conditions of normoxia appear to be important for protecting neurons from oxidative stress.

\section{Materials and Methods}

Desferrioxamine (DFO) and 3,4-dihydroxybenzoate (DHB) were purchased from Sigma Chemicals, dimethyloxalylglycine (DMOG) was purchased from Frontier Scientific Discovery Chemicals. HIF-wt (YGKKRRQRRRDLDLEMLAPYIPMDDDFQL) and HIF-mut (YGKKRRQRRRDLDLEMLAAYIAMDDDFQL) peptides were synthesized by the Biopolymers laboratory, Harvard Medical School, Harvard, MA. 5' -Thiol modified siRNAs for control and isoforms for PHDs were ordered from Qiagen.

Cell culture. Cell cultures were obtained from the cerebral cortex of fetal Sprague Dawley rats [embryonic day 17 (E17)] as described previously (Ratan et al., 1994). HT22 murine hippocampal cells were cultured in Dulbecco modified Eagle's medium with high glucose, L-glutamine, pyridoxine hydrochloride, and 10\% FBS (DMEM; Invitrogen) supplemented with penicillin/streptomycin and 10\% fetal bovine serum (Invitrogen).

Penetratin1-linked siRNA preparation. siRNAs were designed according to published design guidelines with dTdT 3' overhangs (Elbashir et al., 2001a,b; Davidson et al., 2004). Six siRNA sequences were analyzed for each isoform. At least two among each set of 19 nt double-stranded sequences caused significnat knockdown of the respective isoforms: for PHD1 (NM_001004083), CAGCACUACCCAUAGCAGUdTdT and UCAAGCUCUCCCUCAGUUGdTdT; for PHD2 (NM_178334), GAUGUGUGACAUGUAUAUAdTdT and GAGUGACUCUUCCAAGGACdTdT; for PHD3 (NM_019371), UGCCUCUGGGACACAUCAUdTdT and UGGAACAGGUUAUGUUCGUdTdT. All siRNAs target the open reading frame. Commercially available negative control was purchased from Qiagen (cat\# 1027099, Qiagen). For coupling, siRNA duplexes with a 5' -thiol on the sense strand were synthesized and HPLC purified (Qiagen). For uptake studies, siRNAs were synthesized with a $5^{\prime}$ thiol on the sense strand and $5^{\prime}$ rhodimine on the antisense strand. Annealed siRNA duplexes were resuspended in buffer provided by the manufacturer. An equimolar ratio of Penetratin1 
(Q-Biogene) was added to the siRNA suspension, the mixture was heated to $65^{\circ} \mathrm{C}$ for $15 \mathrm{~min}$, and then incubated at $37^{\circ} \mathrm{C}$ for $1 \mathrm{~h}$. The yields of the reactions were estimated at $90 \%$ by SDS-PAGE (data not shown). Penetratin1-linked siRNA was added to the immature cortical neuron. Control siRNAs labeled with a $5^{\prime}$ thiol on the sense strand and $5^{\prime}$ rhodamine on the antisense strand were used to visualize uptake of siRNA into neurons using confocal fluorescence microscope (Ziess LSM50). Real-time PCR and immunocytochemical analysis for the expression of PHD isoforms was performed after $16 \mathrm{~h}$ of incubation with the siRNA.

Plasmids and retroviruses. Short interfering RNAs (siRNA) were cloned into the pSuperRetro vector (OligoEngine) under the control of polymerase-III H1-RNA gene promoter. SiRNAs ShRNAs in pSuperRetro (OligoEngine) that correspond to the HIF- $1 \alpha$ and green fluorescent protein (GFP) genes were designed according to the manufacturer's instructions. The target sequence for HIF-1 and GFP was selected as described previously (Aminova et al., 2005). pSuperRetro shHIF-2 and the pGL2-promoter with 68 bp sequence containing the hypoxia response element from the enolase 1 gene was used to monitor HIF-1 transcriptional activity (Semenza et al., 1994). shGFP sequence was used as a control for the shHIF-2 experiments referred to as control in the figures. CREB and ACREB (dominant negative inhibitor of CREB) plasmids were a kind gift from Dr. David Ginty (Johns Hopkins University, Baltimore, MD) (Ahn et al., 1998).

Transfections and infections. HT22 cells were plated on a 12-well plate at a density of $5 \times 10^{4}$ cells $/ \mathrm{ml} 16 \mathrm{~h}$ before transfection or infection. CREB, ACREB, HRE-luciferase or CRE-luciferase reporter plasmids were transfected using Lipofectamine 2000 (Invitrogen) according to the manufacturer's protocol. Retroviral infections of HT22 cells were performed in the presence of polybrene ( $4 \mu \mathrm{g} / \mathrm{ml}$; Sigma) at a multiplicity of infection (MOI) of 10 and incubated for $24 \mathrm{~h}$ before addition of puromycin ( $4 \mu \mathrm{g} / \mathrm{ml}$; Sigma) containing media for selection.

Cell lysates. After transfection, infection, or drug treatment, cells were scraped into the cold PBS and centrifuged. After washing in cold PBS, the cell pellets were either used for whole-cell lysate preparation using lysis buffer (Boston Bioproducts) added with a protease inhibitors cocktail (Sigma) or subjected to nuclear extraction procedure using NE-PER nuclear and cytoplasmic extraction reagents kit (Pierce Biotechnology).

Immunoblot analysis. Samples were boiled in Laemmli buffer and electrophoresed under reducing conditions on $12 \%$ polyacrylamide gels. Proteins were then transferred to a polyvinylidene difluoride membrane (Bio-Rad). Nonspecific binding was inhibited by incubation in odyssey blocking buffer (Li-Cor Biosciences). Primary antibodies against HIF- $1 \alpha$ (Upstate Cell Signaling Solutions), HIF- $2 \alpha$ (Millipore Bioscience Research Reagents), CREB (Upstate Cell Signaling Solutions), and $\beta$-actin (Sigma), were diluted 1:100, 1:100, 1:1000, and 1:5000 respectively in odyssey-blocking buffer and incubated overnight at $4^{\circ} \mathrm{C}$. Respective fluorophore conjugated odyssey IRDye- 680 or IRD-800 secondary antibodies (LI-COR Biosciences) were used at 1:10,000 dilution followed by incubation for $2 \mathrm{~h}$ at room temperature. Immunoreactive proteins were detected using Odyssey infrared imaging system (LI-COR Biosciences).

Immunofluoroscence staining. Indirect labeling methods were used to determine the levels of PHD isoform protein levels in cortical neuron cultures. Dissociated cells from cerebral cortex were seeded onto poly-Dlysine coated eight-well culture slides (Becton Dickinson Labware) and treated with penetratin 1 linked siRNA against PHD1, PHD2, and PHD3 overnight. Cells were washed with warm PBS and fixed at room temperature for 15 min with $4 \%$ paraformaldehyde (PFA). After washing, cells were incubated with blocking solution containing $0.3 \%$ Triton X-100, and $5 \%$ goat serum in PBS for $1 \mathrm{~h}$, followed by incubation with rabbit PHD1 or -PHD2 antibody (Novus Biologicals) (1:100 dilution) overnight. After three washes with PBS, cells were incubated with FITCconjugated goat-anti-rabbit IgG antibody (Invitrogen) (1:200 dilution) and DAPI. The slides were washed three times with PBS and mounted with Fluorochrome mounting solution (Vector Laboratories). Images were analyzed under confocal fluorescence microscope (Ziess LSM50). Control experiments were performed in the absence of primary antibody.

Real-time and reverse transcriptase-PCR. Real-time PCR was performed to analyze changes in mRNA levels. The levels of CREB, HIF- $1 \alpha$, HIF- $2 \alpha$,

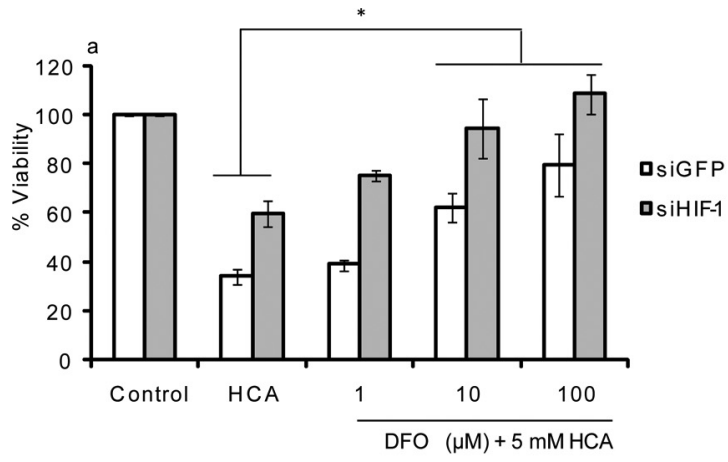

$b$
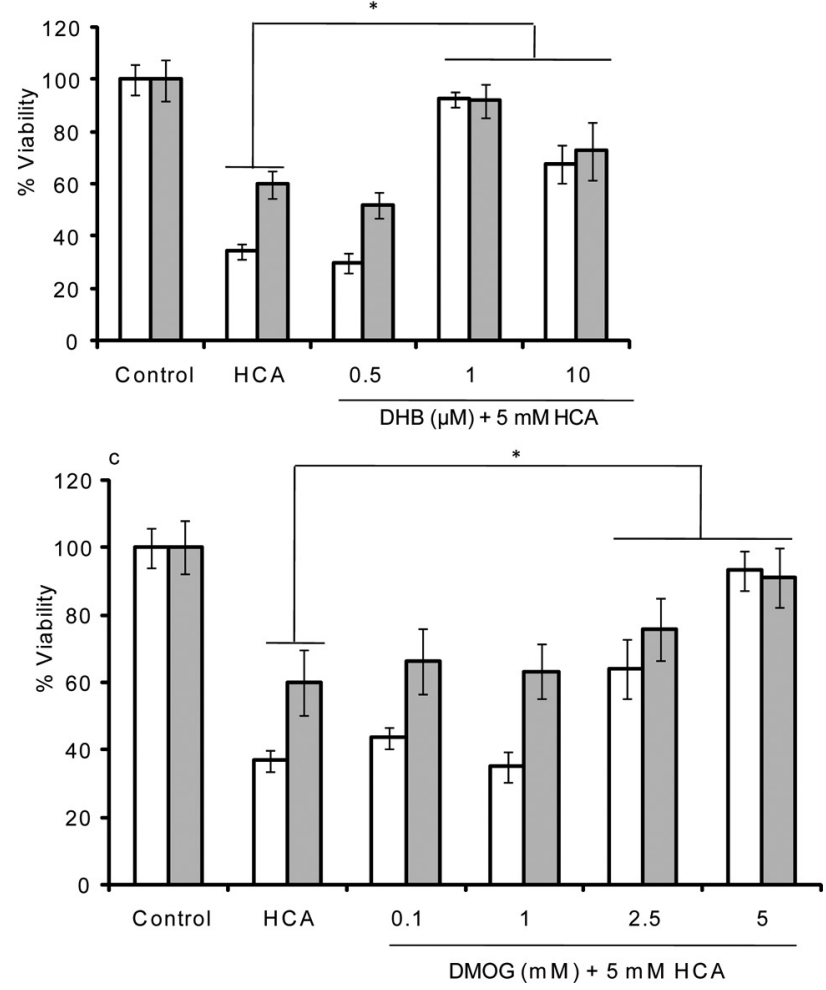

Figure 2. Prolyl 4-hydroxylase inhibition protects neurons from oxidative stress induced death via mechanisms independent of HIF- $1 \alpha$. $\boldsymbol{a}-\boldsymbol{c}$, Percentage viability of siHIF-1- or siGFPinfected HT22 cells under oxidative stress in the presence or absence of varying doses of DFO $(\boldsymbol{a})$, DHB (b), or DMOG (c). Cell viability was measured using MTT assay. Graphs depict mean percentage viability $\pm S D$ calculated from three separate experiments for each group $\left({ }^{*} p \leq 0.05\right.$ by ANOVA and Student-Newman-Keuls tests).

VEGF, p21, and enolase were analyzed using Realtime PCR assay mix and primers (Mm00501607_m1, Mm00468875_m1, Mm00438717_m1, Mm00432448_m1, Mm00469062_m1) (Applied Biosystems) on an Applied Biosystems 7500 system. $\beta$-Actin was used as an endogenous control (Mm00607939_s1). The levels of c-Fos were analyzed by semiquantitative RT-PCR by using the one-step RT-PCR kit ReddyMix version (Abgene) using primers forward 5'AGTGGTGAAGACCATGTCAGG3' and reverse 5'CATTGGGGATCTTGCAGGCAG3'.

Luciferase assay. Cells overexpressing luciferase gene obtained by transfection of HT22 cells with an HRE (enolase 1 promoter-reporter construct) (Semenza et al., 1994) or CRE-luciferase reporter (BDbiosciences, Clontech) were used to study the effects of CREB or HIF-1 knockdown and with or without treatment with PHD inhibitors. Luciferase assay was performed using the bioluminescent method (Promega) using a luminometer plate reader (Molecular Devices). Luciferase activity was normalized to cell viability using 3-(4,5-dimethylthiazol-2-yl)2,5-diphentetrazolium bromide) (MTT) assay or protein concentration using Bio-Rad assay. 


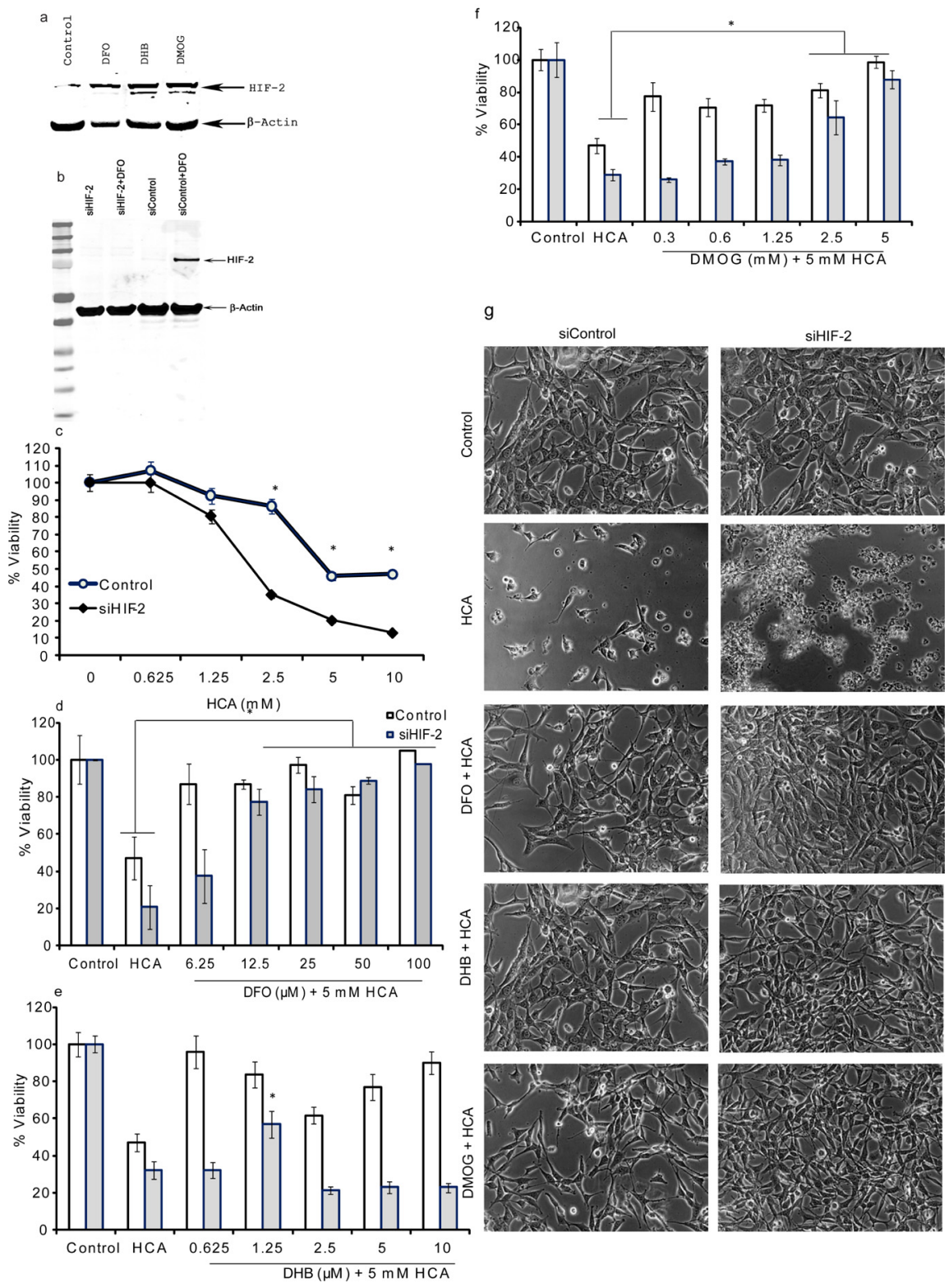

Figure 3. Reduction in HIF-2 levels renders hippocampal neuroblasts more sensitive to oxidative stress both in the presence and absence of HIF-PHD inhibitors. $\boldsymbol{a}$, HIF-PHD inhibitors stabilize HIF-2 $\alpha$. $\boldsymbol{b}$, HT22 cells were stably transfected with a retroviral vectors containing shGFP (control) or shHIF-2 $\alpha$ (siHIF-2 $\alpha$ ) and selected for 1 week using puromycin. Western blot analysis was conducted to analyze reduction in HIF-2 $\alpha$ protein levels in siHIF-2 $\alpha$ (lanes 1 and 2 ) and control (lanes 3 and 4 ) cells in the presence and absence of DFO (lanes 2 and 4). c, Percentage viability of control and siHIF-2 cells after overnight treatment with oxidative stress inducer HCA. $\boldsymbol{d}-\mathbf{f}$, Percentage viability of control or siHIF-2 overexpressing HT22 cells under oxidative stress in the presence or absence of varying doses of DFO (d), DHB $(\boldsymbol{e})$, or DMOG $(\boldsymbol{f})$. Cell viability was measured using MTT assay. Graphs depict mean percentage viability $\pm S D$ calculated from three separate experiments for each group. ${ }^{*} p \leq 0.05$ by ANOVA and StudentNewman-Keuls tests. $g$, Phase-contrast pictures of HT22 cells infected with siControl (left), siHIF-2 (right) cells that were nontreated (control), or treated with HCA (5 mM) in the presence or absence of DFO (100 $\mu \mathrm{M})$, DHB (1.25 $\mu \mathrm{m})$, or DMOG $(5 \mathrm{~mm})$.

Viability assays. For cytotoxicity studies, primary neurons or HT22 cells were isolated or grown as described above. Primary neurons were plated at a density of $10^{6}$ cells/ml in 96-well plates, overnight before treatment with the penetratin1-siRNA complex. After $16 \mathrm{~h}$, cells were rinsed with warm PBS and then placed in minimum Essential Medium (MEM; Life Technologies), containing respective concentrations of the glutamate analog homocysteate (HCA). HCA was diluted from 100-fold concentrated solutions that were adjusted to $\mathrm{pH} 7.5$. Viability was assessed by the MTT assay (Mosmann, 1983). To evaluate the effects of the drugs on cytotoxicity, DFO and DHB were added simultaneously with HCA; DMOG was added for $6 \mathrm{~h}$ and removed from the wells before the addition of HCA. The fidelity of MTT assays in measuring viability was verified by using LIVE/DEAD assay and fluorescence microscopy or phase contrast microscopy as previously described (Siddiq et al., 2005).

Statistics. All experiments were performed in triplicates or more. Data were subjected to twoway ANOVA or multivariate analysis. The statistical significance of differences between means was assessed using Neumann-Keuls post hoc tests, as indicated in table and figure legends. The analyses were done by using the Statistica 6.1 software (StatSoft).

\section{Results}

To test whether HIF- $1 \alpha$ is indeed required for HIF-PHD inhibition to exert its neuroprotective effects, we first established a line of immortalized hippocampal neuroblasts (HT22 cells) in which we could knock down endogenous HIF- $1 \alpha$ expression by RNA interference. (HIFs are heterodimeric complexes comprising regulated $\alpha$ subunits and constitutively expressed $\beta$ subunits; it is the $\alpha$-subunit that is hydroxylated at two proline residues in the oxygen-dependent degradation domain, which allows for ubiquitination and degradation). We used a retroviral DNA vector that processes short interfering RNAs from a short RNA hairpin (shRNA) transcribed under control of the polymerase III-H1 promoter (pSuperretro, Oligoengine), selecting a 19-nt-long sequence targeting HIF-1 and a control GFP sequence. At least three stable cell pools expressing each of these shRNAs were generated and selected with puromycin. Expression of the hpGFP (siGFP) caused no change in HIF-1 $\alpha$ message expression compared with controls, whereas expression of the shHIF-1 (siHIF-1) significantly reduced HIF- $1 \alpha$ message by $\sim 60 \%$ (Fig. 1a).

To verify reduction in HIF- $1 \alpha$ protein levels, we turned to three canonical PHD inhibitors-DFO (an iron chelator), DMOG (a 2-oxoglutarate analog), and DHB (a 2-oxoglutarate analog). We had previously showed that PHD inhibition by these small molecules stabilizes HIF- $1 \alpha$ levels and is associated with significant transactivation of a luciferase reporter gene (Siddiq et al., 2005). Control cells infected with siGFP showed robust luciferase activity, but HIF- $1 \alpha$ depleted cells showed little response to PHD inhibition (Fig. 1b). These findings affirm prior studies that show that our shRNA to HIF- $1 \alpha$ reduces protein levels in hippocampal neuroblasts (Aminova et al., 2005).

We next verified that HIF-1 repression reduced expression of known HIF-1 target genes. We performed real-time PCR on enolase, p21 waf1/cip1, and VEGF mRNAs (Semenza, 2000), using $\alpha$-tubulin as a control. As expected, DFO, DHB, and DMOG robustly increased mRNA levels of the three HIF-1 targets (eno- 
lase, $p 21$, and VEGF) in siGFP-expressing cells but not siHIF cells (Fig. 1c), whereas the increase in mRNA levels of the HIF-1 target genes was significantly reduced in the siHIF cells. An oxygen insensitive HIF-VP16 construct rescued HIF-dependent gene expression in the presence of the shRNA to HIF- $1 \alpha$ (data not shown). We conclude that the effects of shRNA to HIF- $1 \alpha$ are target-specific.

\section{Neuroprotective effect of PHD inhibition does not require HIF-1}

Previous work showed that the absence of HIF- $1 \alpha$ protects HT22 cells against glutathione depletion-induced cytotoxicity (Aminova et al., 2005). To determine whether the absence of HIF- $1 \alpha$ nullifies the neuroprotective effect of PHD inhibition against oxidative stress-induced death, we measured the viability of shHIFand shGFP-expressing cells exposed to $5 \mathrm{~mm}$ of the glutamate analog HCA, with and without the addition of various doses of DFO, DHB, or DMOG. HCA competitively inhibits cystine uptake into immature primary neurons, depleting intracellular cysteine, the rate-limiting precursor of glutathione synthesis (Ratan et al., 2002). Surprisingly, not only was PHD inhibition still protective in the absence of HIF- $1 \alpha$, but loss of HIF- $1 \alpha$ made cells more sensitive to PHD inhibition at lower concentrations of DFO, DHB, and DMOG (Fig. $2 a-c$ ). PHD inhibitors thus protect neurons from oxidative stress-induced death via mechanism(s) independent of HIF-1. Indeed, these results suggest that under normoxic conditions, HIF-1 expression in neurons diminishes the potency and efficacy of HIF-PHD inhibition-induced neuroprotection.

\section{Loss of HIF-2 renders hippocampal neurons more sensitive to} oxidative stress regardless of HIF-PHD inhibition

HIF- $2 \alpha$, also known as endothelial PAS domain protein-1, shares $80 \%$ sequence homology to HIF- $1 \alpha$ and also interacts with HIF-1 $\beta$. Treatment of immortalized hippocampal cells (data not shown) or primary cortical neurons with HIF-PHD inhibitors increases HIF- $2 \alpha$ protein levels (Fig. $3 a$ ). We therefore asked whether HIF- $2 \alpha$ could be mediating the neuroprotective effects of HIF-PHD inhibition. We expressed a previously validated shRNA against HIF- $2 \alpha$ in HT22 cells, as described above for HIF- $1 \alpha$. The HIF $2 \alpha$ shRNA significantly reduced its protein levels (Fig. $3 b$ ) and message levels by $>90 \%$ in HT22 cells (data not shown). We then treated control and HIF-2 knockdown cells with varying doses of the glutamate analog HCA. Increasing concentrations of HCA reduced viability of both cell lines, but consistent with previous results (Shohet and Garcia, 2007; Lomb et al., 2009) those lacking HIF-2 were more sensitive to the glutathione depletion (Fig. 3c). PHD inhibition by DFO and DMOG is still completely protective in these cells, but protects less potently than in control cells. DHB was only effective in HIF-2 depleted cells at a relatively low dose of $1.25 \mu \mathrm{M}$, but still only $\sim 60 \%$ cells were viable (Fig. $3 d-g$ ). These data suggest that HIF-2 affects the potency but not efficacy of two structurally diverse PHD inhibitors, DFO and DMOG, in preventing oxidative death. The DHB dose-response in the absence of HIF-2 becomes much more parabolic, suggesting that HIF-2 may be important in combating off-target toxic effects of DHB as its concentration is increased under conditions of oxidative stress.

Knockdown of HIF-1 in HIF-2 deficient cells diminishes their vulnerability to oxidative stress-induced death

Our results so far indicate that loss of HIF-1 protects hippocampal neuroblasts against oxidative stress, whereas loss of HIF-2
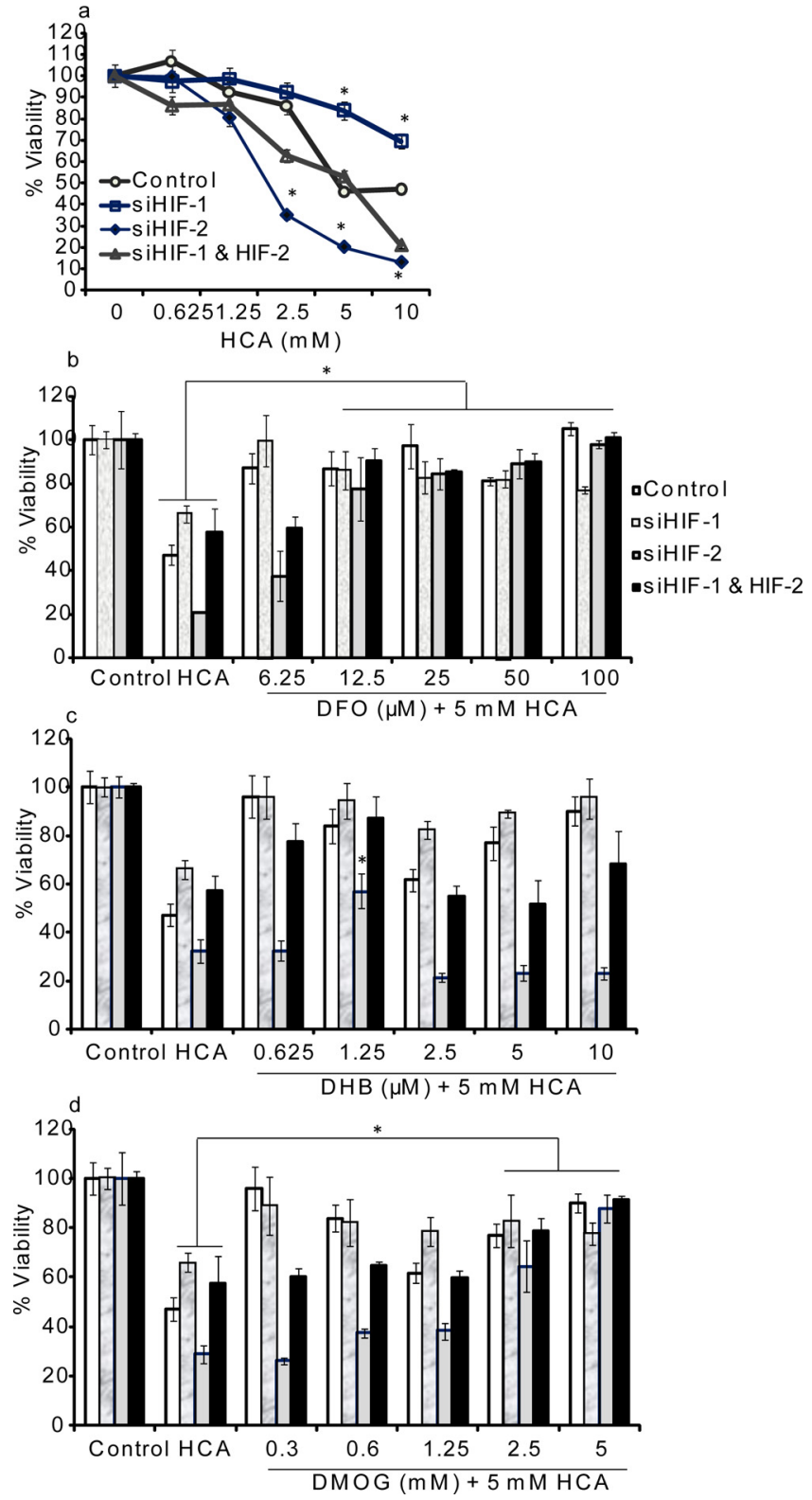

Figure 4. Knockdown of HIF-1 in HIF-2 deficient cells partially abrogates the sensitivity of HIF-2 knock-out hippocampal cells to oxidative stress induced death. $\boldsymbol{a}-\boldsymbol{d}$, Cells overexpressing siRNA against HIF- $1 \alpha$, HIF- $2 \alpha$, or both HIF- $1 \alpha$ and HIF- $2 \alpha$ simultaneously were subjected to varying doses of oxidative stress inducer HCA $(\boldsymbol{a})$ or in the presence or absence of DFO $(\boldsymbol{b}), \mathrm{DHB}$ (c), or DMOG (d); percentage cell viability was measured after overnight treatments with the drugs and HCA, using MTT assay. Graphs depict mean percentage viability \pm SD calculated from three separate experiments for each group $\left({ }^{*} p \leq 0.05\right.$ by ANOVA and Student-Newman-Keuls tests.

makes them more vulnerable. We therefore examined the effect of simultaneous reduction in both HIF-1 and HIF-2 and found that doubly deficient cells are about as vulnerable to oxidative stress as control cells; HIF-1 knockdown cells remain most protected, HIF-2 knockdown cells remain the most sensitive to oxidative stress induced death (Fig. 4a). This was the case regardless of PHD inhibition status (Fig. $4 b-d$ ). Notably, the absence of HIF-1 improved the performance of all three PHD inhibitors, enabling full rescue by DFO and DMOG and almost complete rescue by $\mathrm{DHB}$ at the lowest dose. These data are in agreement with previous reports that HIF- $1 \alpha$ may act as a prodeath molecule (Aminova et al., 2005), and further suggest that HIF-2 $\alpha$ has 

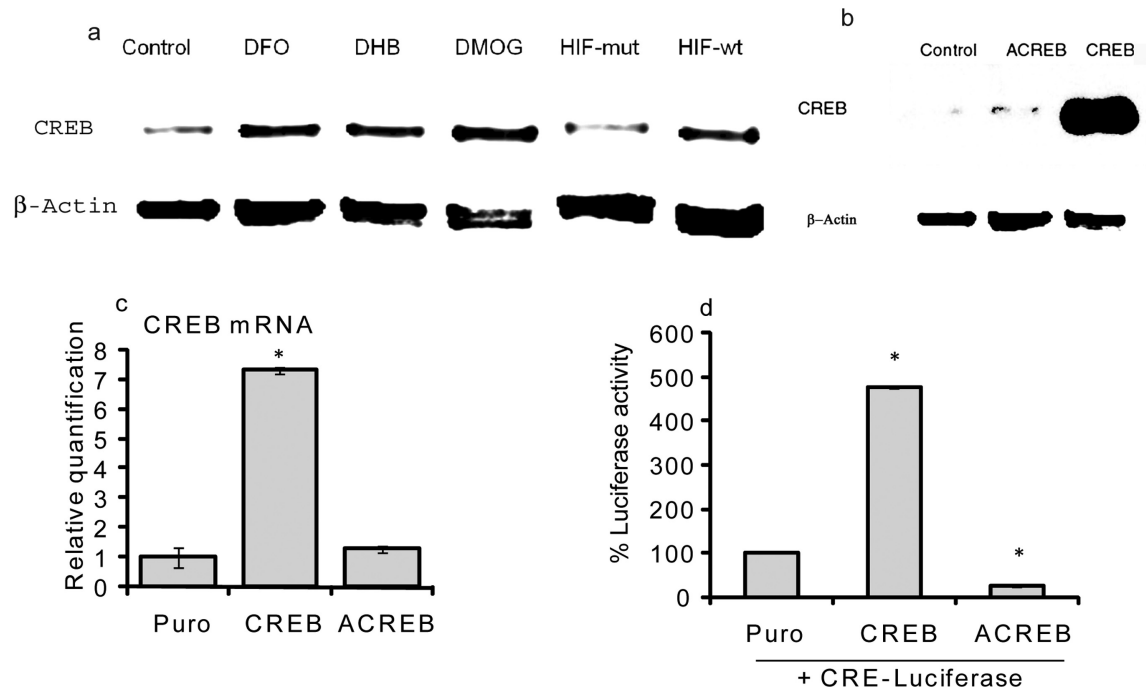

Figure 5. Characterization of CREB and ACREB. $\boldsymbol{a}$, Western blot analysis of neurons treated with pharmacological (DF0, DHB, and DMOG: lanes 2-4) or peptide (HIF-wt: lane 6) inhibitors to analyze total CREB levels. HIF-mut (lane 5) and nontreated cells (lane 1) were used as controls. $\boldsymbol{b}$, Western blot analysis of CREB protein levels after stable transfection of HT22 cells with control (lane 1), ACREB (lane 2), or CREB (lane 3). c, Real-time PCR analysis of CREB mRNA levels in HT22 cells stably transfected with control (empty), CREB or ACREB plasmids. $\boldsymbol{d}$, Percentage luciferase activity in control, CREB, or ACREB stably overexpressing cells after transient transfection with the CRE-luciferase reporter. ${ }^{*} p \leq 0.05$ by ANOVA and Student-Newman-Keuls tests. signal in the HT22 cell lines (Fig. $5 b-d$ ). To verify that changes in CRE dependent reporter accurately reflected CREB transcriptional activity, we examined the expression of a canonical neuronal CREB target gene, c-fos. Levels of c-fos were significantly elevated in CREB overexpressing cells, whereas overexpression of A-CREB reduced $\mathrm{c}$-fos levels (data not shown). To ascertain the effect of CREB or ACREB overexpression on oxidative stress induced death, we treated cells with a range of concentrations of the glutamate analog HCA but observed no significant difference in the viability of control (puro), CREB, or ACREB cell lines (Fig. $6 a)$. Nor did we observe any significant difference in the effects of PHD inhibition in cells overexpressing CREB or ACREB (Fig. 6b). These results establish that CREB is not necessary for the neuroprotective effects of PHD inhibition nor is CREB sufficient to mimic PHD inhibition induced neuroprotection.

Simultaneous knockdown of HIF-1 and a distinct role in protecting against normoxic oxidative death. The findings also add to a growing body of literature that suggests that HIF-1 and HIF-2 may have complementary rather than redundant functions (Imamura et al., 2009; Mastrogiannaki et al., 2009).

\section{Neuroprotection by PHD inhibition does not depend on CREB}

The transcription factor CREB plays a role in protecting multiple neuronal types from programmed cell death in response to different apoptotic stimuli, including ischemia or growth factor withdrawal (Valera et al., 2008; Atkinson et al., 2009). Hypoxia increases its activity (O'Reilly et al., 2006), and we previously showed that DFO stimulates CREB binding to the hypoxia response element in rat primary neurons (Zaman et al., 1999). We therefore sought to determine the effect of PHD inhibitors on CREB. Real-time PCR and immunoblotting revealed a significant increase in CREB mRNA and total protein levels in the HT22 cells treated with DFO, DHB, and DMOG. To verify that these small molecules are targeting the HIF prolyl hydroxylases, we used a previously validated cell permeant, peptide inhibitor (HIF-wt) of the HIF PHDs. A mutated form of the peptide (HIF-mut) was used as a control (Siddiq et al., 2005) (Fig. 5a). Of note, these cells also showed an increase in the phosphorylated form of CREB (data not shown), but we have not established whether this reflects increased phosphorylation of CREB or constitutive phosphorylation of an increased pool of CREB.

We next sought to determine whether CREB mediates the protective effect of HIF-PHD inhibition. We forced expression of either wild-type CREB or a dominant-negative form of the protein in which an acidic domain has been substituted for the leucine zipper domain (ACREB) (Ahn et al., 1998) (to functionally knock down the CREB protein). We then verified that each of the proteins had the expected effect on CREB transcriptional activity by using a luciferase reporter driven by a canonical CRE sequence. As expected, CREB overexpression strongly stimulated CRE reporter activity, whereas ACREB reduced the luciferase

\section{CREB does not abrogate protective effect of PHD inhibition} Although PHD inhibition increases both HIF-1 and CREB levels in neurons, knockdown of one does not eliminate possible compensation provided by the induction of the other. We transfected puromycin resistance gene (control), CREB-, or ACREBoverexpressing cell lines with the HRE-Luc plasmid and treated the cells with DFO and DHB. As shown in Figure $6 d$, simultaneous knock-out of both CREB and HIF-1 had no influence on the neuroprotective effects of PHD inhibition. We conclude that prolyl 4-hydroxylase enzymes protect neurons from oxidative stress induced death via mechanisms independent of HIF-1 and CREB.

\section{Knockdown of isoform PHD1 but not PHD2 or 3 abrogates oxidative stress-induced death in cortical neurons}

Neurons express three distinct isoforms of prolyl 4-hydroxylase enzymes: PHD-1, PHD2, and PHD3. The three isoforms differ in expression regulation, tissue distribution, cellular localization, and ability to hydroxylate HIF- $1 \alpha$ (Siddiq et al., 2007); they share homology in the C-terminal catalytic domain but differ considerably in $\mathrm{N}$-terminal sequences. We previously showed that global inhibition of all three isoforms of prolyl 4-hydroxylase prevents oxidative glutamate toxicity in primary neurons and reduces injury in a rat model of middle cerebral artery occlusion (Siddiq et al., 2005). Our findings that HIF is unnecessary for protection by global HIF-PHD inhibitors led us to hypothesize that the isoform most associated with HIF regulation, PHD2, was unlikely to be responsible for protection. But are PHD1 and/or $\mathrm{PHD} 3$ responsible for mediating protection?

We used six separate sequences of siRNA to knockdown each isoform in rat immature primary neurons. Rhodamine-labeled penetratin1-linked siRNA was used to trace delivery of the siRNA in immature primary neurons, and the level of intracellular accumulation of the siRNA was monitored by fluorescence microscopy. Each cell nucleus, identified by DNA intercalating chromophore DAPI, was found to be associated with rhodamine label in its cell bodies and processes, reflecting the uptake of the 

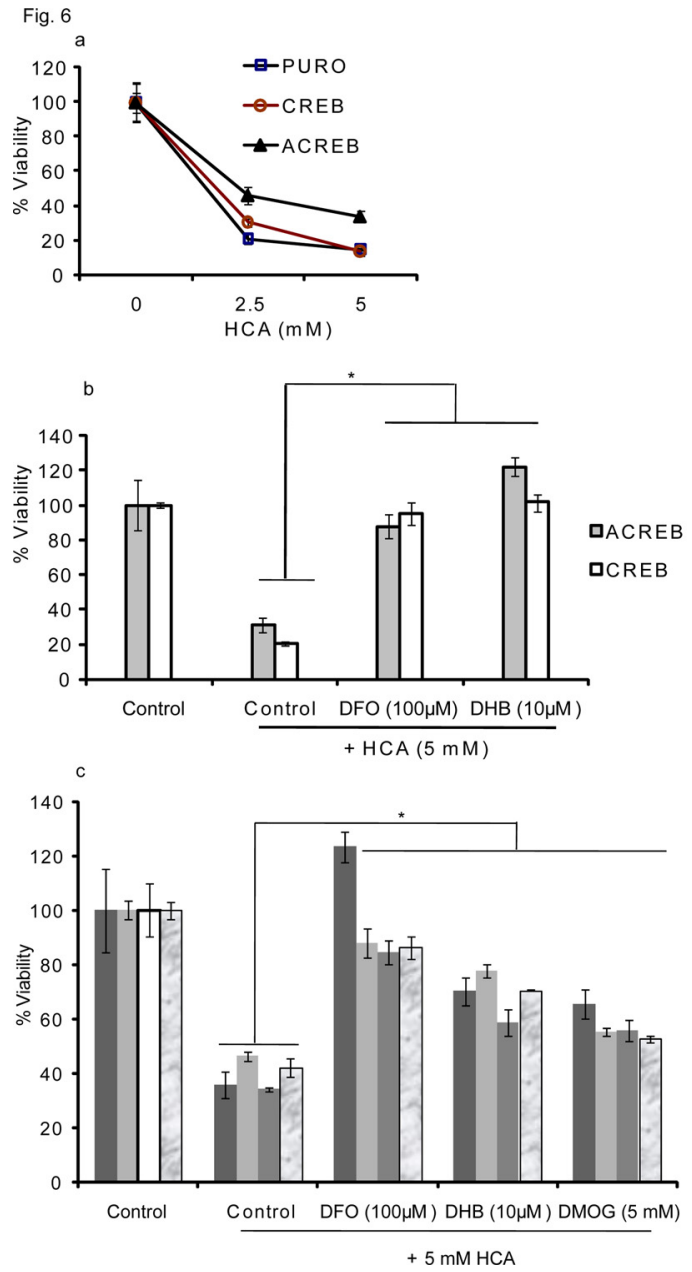

CREB-SiHIF-1 ACREB-SiHIF-1 - CREB-SIGFP $\square$ ACREB-SiGFP

Figure 6. Prolyl 4-hydroxylase inhibition protects neurons from oxidative stress induced death via mechanisms independent of CREB. $\boldsymbol{a}$, Percentage viability of control, CREB, or ACREB cell lines treated with varying doses of HCA overnight. $\boldsymbol{b}, \mathrm{HT} 22$ cells transfected with ACREB or CREB, cells nontreated (control), or treated with HCA $(5 \mathrm{~mm})$ in the presence or absence of DFO $(100 \mu \mathrm{M})$ or DHB $(10 \mu \mathrm{M})$. Cell viability was measured using MTT assay. Graphs depict mean percentage viability $\pm S D$ calculated from three separate experiments for each group $\left({ }^{*} p \leq\right.$ 0.05 by ANOVA and Student-Newman-Keuls tests). c, (REB or ACREB overexpressing cells were infected with siHIF-1 or siGFP and subjected to oxidative stress induced death in the presence or absence of DFO or DHB.

rhodamine-penetratin1-siRNA complex (Fig. 7a). Cells treated with penetratin1-linked siControl and six sequences against PHD1 (siPHD1), PHD2 (siPHD2), or PHD3 (siPHD3) were subjected to real-time PCR and immunocytochemistry, which confirmed a significant reduction in both mRNA and protein levels of each isoforms by at least two of the tested sequences as denoted by ${ }^{\star}($ Fig. $7 b-d)$. To determine the effect of knockdown of each PHD isoform on oxidative stress induced death, PHD isoform knockdown cells were exposed to a glutamate analog HCA (5 mM). Knockdown of PHD1 but not PHD2 or PHD3 prevented oxidative stress-induced death in neurons as measured by MTT assay or qualitative observation by phase contrast microscopy (Fig. $8 a, b$ ). Consistent with previous observations that HIF-PHD2 is the central regulator of hypoxia gene expression in neurons, we found that molecular reduction of PHD1 did not increase the activity of a luciferase reporter driven by a hypoxia response element (data not shown).
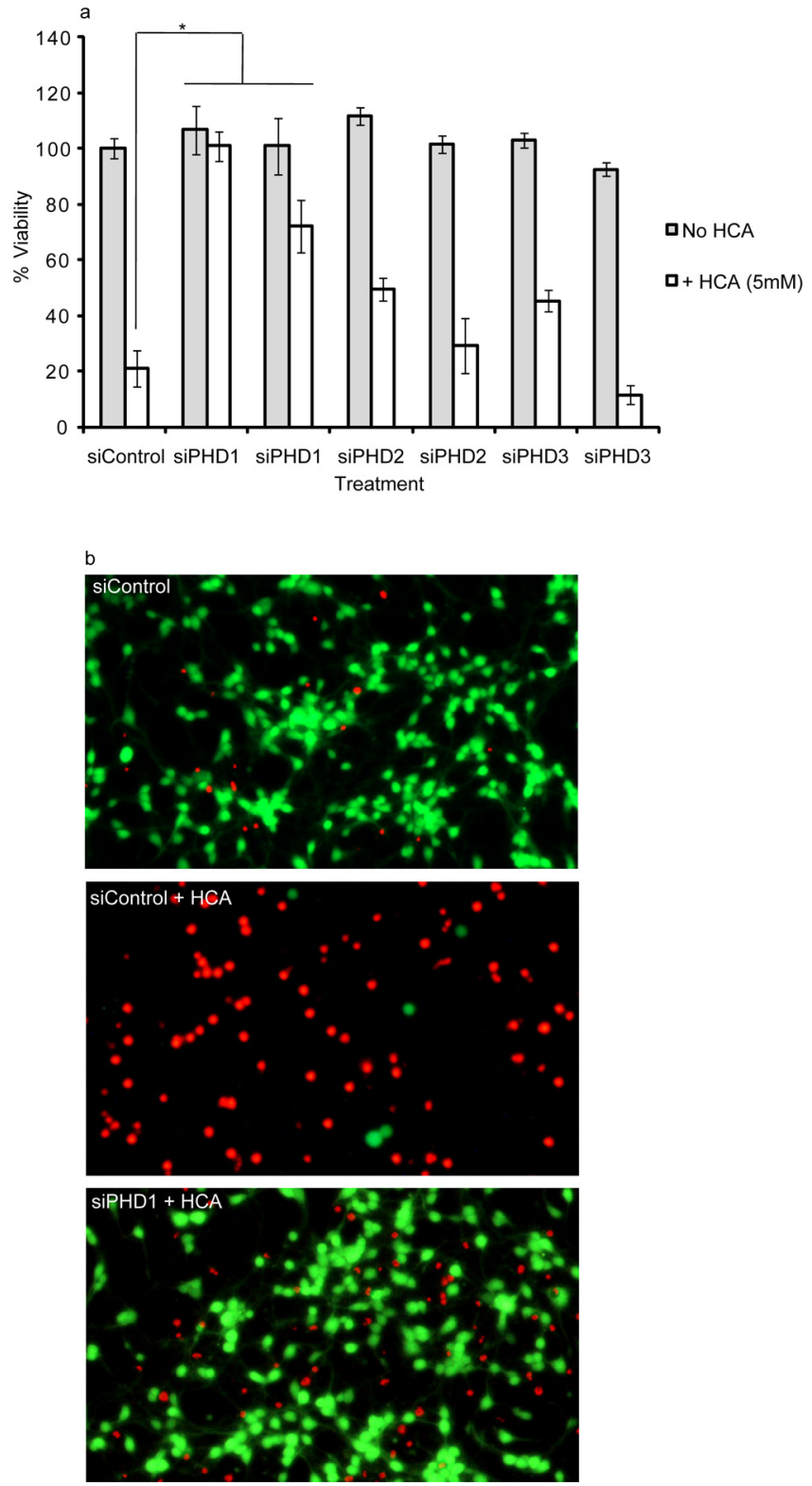

Figure 8. The knockdown of the isoform of prolyl 4-hydroxylase enzymes PHD1 but PHD2 or PHD3 abrogates oxidative stress-induced death in cortical neurons. $\boldsymbol{a}$, Percentage viability of primary neurons treated with siControl or two separate siRNAs against each isoform PHD1, PHD2, or PHD3. Control or knockdown cells were exposed to oxidative stress overnight, viability was measured using MTT assay. Graph depicts mean percentage viability (compared with control) $\pm S D$ calculated from three separate experiments for each group $\left({ }^{*} p \leq 0.05\right.$ by ANOVA and Student-Newman-Keuls tests). $\boldsymbol{b}$, Live/dead assay of cortical neuronal cultures treated with siControl or siRNA against PHD1 in the presence or absence of HCA $(5 \mathrm{~mm})$. Live cells are detected by uptake and trapping of calcein-AM (green fluorescence). Dead cells fail to trap calcein but are freely permeable to the highly charged DNA intercalating dye, ethidium homodimer (red fluorescence).

\section{Discussion}

Low molecular weight chelators or protein chelators of iron are known to prevent neurodegeneration in a range of disease models. These preclinical studies have paved the way for ongoing clinical trials of iron chelators in stroke, Friedreich's ataxia, Parkinson's disease, and spinal cord injury (Cleland et al., 1982; Whitnall and Richardson, 2006; Petri et al., 2007; Amit et al., 2008; Blat et al., 2008; Forni et al., 2008; Kakhlon et al., 2008; Ratan et al., 2008; Weinberg and Miklossy, 2008; Xu et al., 
a

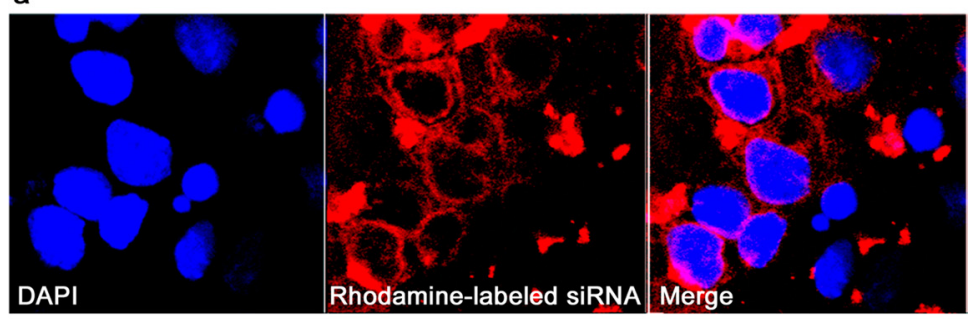

b

PHD isoform mRNA levels
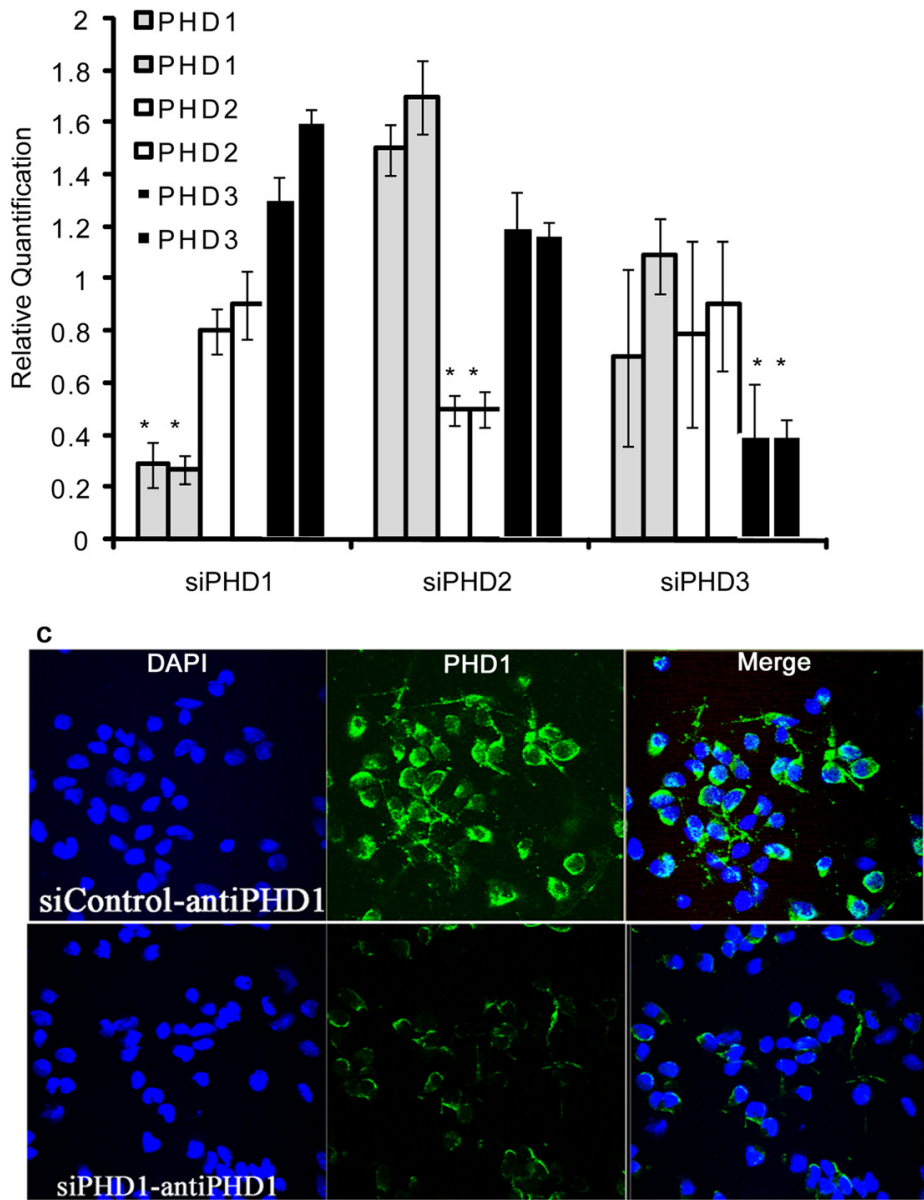

d
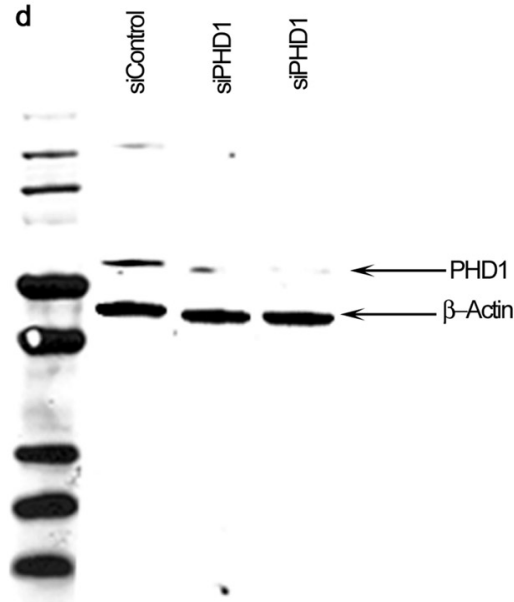

Figure 7. Characterization of penetratin1-linked siRNA against HIF-PHD isoforms. $\boldsymbol{a}$, Primary cortical neurons treated with penetratin1-siRNA labeled with rhodamine (middle) and stained with DAPI (left) to visualize nuclei, and images were merged (right). Six siRNA sequences for each isoform were analyzed for knockdown. $\boldsymbol{b}$, Real-time PCR analysis of HIF-PHD isoforms PHD1, PHD2, and PHD3 from primary neurons treated with penetratin1-linked siRNA against each isoform. Each bar represents mRNA 2008a,b; Gulyani et al., 2009; Wang et al., 2009). Despite these important advances, a firmer understanding of the molecular target(s) of iron chelation in neural cell types may provide strategies to improve safety and pharmacodynamics of these agents. Studies from our laboratory and others over the past 15 years have implicated the HIF-PHDs as targets for neuroprotection by low molecular weight iron chelators and iron-independent HIF-PHD inhibitors (DMOG, DHB) against oxidative stress. Specifically, our model was that DFO, DHB, and DMOG inhibit the HIFPHDs and stabilize three transcriptional activators (HIF-1, HIF-2, and CREB). These transcription factors bind to cognate hypoxia response sequences $\left(5^{\prime}\right.$ RCGTG- $3^{\prime}$, where $\left.r=\mathrm{G} / \mathrm{C} / \mathrm{T} / \mathrm{A}\right)$ to transactivate a well studied and coordinated cassette of adaptive genes. Here, we show that molecular suppression of each of these factors individually or in combination diminishes their transactivation ability but fails to abrogate the neuroprotective effect of DFO. Indeed, consistent with previous results from our laboratory and others, decrease expression of HIF- $1 \alpha$ improves the potency of DFO, DHB, and DMOG in abrogating oxidative death, suggesting that the prodeath effects of HIF-1 dominate in our glutathione depletion model in normoxic, immortalized hippocampal neuroblasts. Future studies will examine whether germline HIF-1 deletion in vivo in astrocytes and neurons potentiates the protective effects of HIFPHD inhibition. Indeed, our studies involving a $60 \%$ reduction in HIF- $1 \alpha$ message via an shRNA approach do not allow us to exclude the possibility that complete suppression of HIF- $1 \alpha$ via conditional or germline deletion would affect protection by HIF PHD inhibitors.

Molecular suppression of HIF- $2 \alpha$ increased the basal sensitivity to oxidative death, as others have reported (Lomb et al., 2009; Nanduri et al., 2009). HIF2 is now known to regulate antioxidant genes and iron homeostasis (Scortegagna et al.,

\footnotetext{
levels after treatment with a different siRNA sequence against that particular isoform, $\left(^{*}\right)$ denotes significant reduction in mRNA levels; the two sequences showing significant reduction in mRNA levels were used for viability experiment shown in Figure $8, a$ and $b . c$, Immunocytochemical analysis of primary neurons treated with siControl (top) and SiPHD1 (bottom). Cells treated with siControl or siPHD1 were stained with DAPI (top and bottom left) and PHD1-specific antibody (top and bottom middle). Top and bottom left panel shows the merge. $\boldsymbol{d}$, Western blot analysis of primary neurons treated with siControl or siPHD1.
} 
2005; Mastrogiannaki et al., 2009), and thus its deletion may perturb the homeostasis of radicals and or metals and lead to oxidative death. Although HIF-2 appears to be important for steady state NGF-induced survival of sympathetic neurons (Lomb et al., 2009), it was not necessary for steady state survival of HT22 hippocampal neuroblasts (Fig. 2). Future studies using conditional deletion of HIF-2 in distinct neurons of the CNS will define those neuronal populations, if any, which are lost and/or sensitized to exogenous injury in response to HIF-2 deletion in vivo. The lack of dependence of basal viability on HIF-2 expression in hippocampal neuroblasts allowed us to define whether HIF-2 is necessary for the protective effects of DFO, DHB, or DMOG (Fig. 3). Indeed, we found that although DFO and DMOG shifted their $\mathrm{IC}_{50} \mathrm{~s}$ considerably in the absence of HIF-2, the compounds were still able to protect (Fig. 3). Our findings do not allow us to distinguish whether the shift reflects increased reactive oxygen species in response to a similar level of glutathione depletion in HIF-2 deficient neuroblasts (Lomb et al., 2009), or that DFO and DMOG possess redundant mechanisms for protection against oxidative death that engage at higher concentrations. In contrast to DFO and DMOG, DHB protected HIF-2 deficient neuroblasts at $1.25 \mu \mathrm{M}$ but not at higher concentrations, suggesting that as higher concentrations are applied, toxicity dominates and nullifies antioxidant protective mechanisms.

Another important aspect of our study is the demonstration that CREB message and protein levels are increased by HIF-PHD inhibition in neuroblasts and neurons (Fig. 5). These findings confirm previous studies from our laboratory that showed that low molecular weight inhibitors of the HIF-PHDs enhance binding of HIF and ATF-1/CREB to the hypoxia response element in a gel shift assay (Zaman et al., 1999). Other studies have demonstrated a role for HIF-PHD inhibition in the stabilization and/or activation of HIF- $1 \alpha$ (Kaelin and Ratcliffe, 2008), HIF-2 $\alpha$ (Aragonés et al., 2008), NF- $\kappa \mathrm{B}$ (nuclear factor $\kappa \mathrm{B}$ ) (Cummins et al., 2006), or JunD (Gerald et al., 2004). However, this is the first study to show that CREB message and protein are induced by HIF-PHD inhibition. The protein sequence data base shows that CREB does not have a proline rich hydroxylation motif (LXXLAP) characteristic of proteins that are hydroxylated by HIFPHDs (Huang et al., 2002). These data along with the increase in CREB message suggest that HIF-PHDs must regulate the activity of a transcription factor involved in regulating CREB expression or alternatively regulate a protein essential for CREB message stability. The known regulation of RNA binding proteins that alter mRNA stability and translational efficiency by hypoxia provides a potential model for the changes in CREB we observe (Zimmer et al., 2008). Despite its clear regulation by HIF-PHDs, CREB does not appear to play a significant role in HIF-PHD inhibition induced neuroprotection. Future studies will clarify the role of CREB in the adaptive response to hypoxia in neurons.

The most unexpected and interesting aspect of our study is the implication of PHD1 in oxidative neuronal death in neurons. A previous elegant study by Lee et al. (2005) has established a concrete role for PHD3 in neuronal death induced by trophic factor deprivation in vivo. Indeed, the PHD3 null mice have larger sympathetic ganglia (Bishop et al., 2008). Our study suggests that the role of PHD3 is cell-type and stimulus specific as PHD3 deletion had no effect on oxidative death (Fig. 8). In contrast, muscle cells in PHD1 mice have been shown to be metabolically reprogrammed so that their basal oxygen consumption is lowered, but they are resistant to ischemia (Aragonés et al., 2008). In this previous study, the protective effects of PHD1 deletion could not be attributed to angiogenesis, vasodilation, or erythropoiesis, but consistent with the results presented herein, to reductions in oxidative stress. According to this model, cells that are deficient in PHD1 upregulate HIF-2 and PPAR $\gamma$, induce glycolytic gene expression, and via PDK4, suppress mitochondrial oxidative phosphorylation. As electron leak from the mitochondrial electron transport chain is a large source of superoxide in cells, reductions in tricarboxylic acid cycle and mitochondrial electron transport in PHD1-deleted cells enjoy reduced ambient free radical burden. Whereas this model is obviously well substantiated for muscle, our data argue that PHD1 deletion must also lead to HIFindependent paths to reduced sensitivity to oxidative stress (Figs. $1,2)$. An interesting possible HIF-independent target for PHD1 is one of the subunits of RNA polymerase II complex, a crucial modulator of gene expression (Mikhaylova et al., 2008). Recent studies have shown that Rbp1, the subunit that carries the fundamental enzymatic activity of the complex in synthesizing many cellular mRNAs, is a target for PHD1-mediated hydroxylation at P1465 within a canonical LGQLAP motif. It is formally possible that hydroxylation at this site is important in targeting RNApol II to genes associated with death or increased susceptibility to oxidative stress. In this scheme, deletion of PHD1 would diminish Rbp1 hydroxylation and suspend gene expression of deleterious genes. Studies are underway to examine this model in neurons. From a therapeutic standpoint, the findings herein add to a growing body of literature that suggest that HIF-PHDs are targets for neuroprotection in neurological and non-neurological conditions associated with oxidative stress. The findings also provide circumstantial evidence that a target for iron chelator mediated neuroprotection is PHD1, an iron, oxygen, and 2-oxoglutarate dependent dioxygenase. Future studies that conditionally delete PHD1 in distinct neuronal populations in adulthood of mice will examine the link between inhibition of this enzyme and neurological conditions such as stroke, $\mathrm{PD}, \mathrm{HD}$, and $\mathrm{AD}$ where oxidative stress has been implicated. The results of these studies could set the table for the development of HIF-PHD isoform selective inhibitors for preclinical and clinical use. At the very least, modulating distinct HIF-PHDs will allow us to optimize HIFdependent and HIF-independent paths of hypoxic adaptation for therapeutic benefit.

\section{References}

Ahn S, Olive M, Aggarwal S, Krylov D, Ginty DD, Vinson C (1998) A dominant-negative inhibitor of CREB reveals that it is a general mediator of stimulus-dependent transcription of c-fos. Mol Cell Biol 18:967-977.

Aminova LR, Chavez JC, Lee J, Ryu H, Kung A, Lamanna JC, Ratan RR (2005) Prosurvival and prodeath effects of hypoxia-inducible factorlalpha stabilization in a murine hippocampal cell line. J Biol Chem 280:3996-4003.

Aminova LR, Siddiq A, Ratan RR (2008) Antioxidants, HIF prolyl hydroxylase inhibitors or short interfering RNAs to BNIP3 or PUMA, can prevent prodeath effects of the transcriptional activator, HIF-1alpha, in a mouse hippocampal neuronal line. Antioxid Redox Signal 10:1989-1998.

Amit T, Avramovich-Tirosh Y, Youdim MB, Mandel S (2008) Targeting multiple Alzheimer's disease etiologies with multimodal neuroprotective and neurorestorative iron chelators. FASEB J 22:1296-1305.

Aragonés J, Schneider M, Van Geyte K, Fraisl P, Dresselaers T, Mazzone M, Dirkx R, Zacchigna S, Lemieux H, Jeoung NH, Lambrechts D, Bishop T, Lafuste P, Diez-Juan A, Harten SK, Van Noten P, De Bock K, Willam C, Tjwa M, Grosfeld A, et al. (2008) Deficiency or inhibition of oxygen sensor Phd1 induces hypoxia tolerance by reprogramming basal metabolism. Nat Genet 40:170-180.

Atkinson T, Whitfield J, Chakravarthy B (2009) The phosphatase inhibitor, okadaic acid, strongly protects primary rat cortical neurons from lethal oxygen-glucose deprivation. Biochem Biophys Res Commun 378:394-398

Bishop T, Gallagher D, Pascual A, Lygate CA, de Bono JP, Nicholls LG, 
Ortega-Saenz P, Oster H, Wijeyekoon B, Sutherland AI, Grosfeld A, Aragones J, Schneider M, van Geyte K, Teixeira D, Diez-Juan A, LopezBarneo J, Channon KM, Maxwell PH, Pugh CW et al. (2008) Abnormal sympathoadrenal development and systemic hypotension in PHD3-/mice. Mol Cell Biol 28:3386-3400.

Blat D, Weiner L, Youdim MB, Fridkin M (2008) A Novel iron-chelating derivative of the neuroprotective peptide NAPVSIPQ shows superior antioxidant and antineurodegenerative capabilities. J Med Chem 51:126-134.

Bruick RK, McKnight SL (2001) A conserved family of prolyl-4hydroxylases that modify HIF. Science 294:1337-1340.

Cleland LG, Betts WH, Vernon-Roberts B, Bielicki J (1982) Role of iron and influence of antiinflammatory drugs on oxygen-derived free radical production and reactivity. J Rheumatol 9:885-892.

Cummins EP, Berra E, Comerford KM, Ginouves A, Fitzgerald KT, Seeballuck F, Godson C, Nielsen JE, Moynagh P, Pouyssegur J, Taylor CT (2006) Prolyl hydroxylase-1 negatively regulates IkappaB kinase-beta, giving insight into hypoxia-induced NFkappaB activity. Proc Natl Acad Sci U S A 103:18154-18159.

Davidson TJ, Harel S, Arboleda VA, Prunell GF, Shelanski ML, Greene LA, Troy CM (2004) Highly efficient small interfering RNA delivery to primary mammalian neurons induces MicroRNA-like effects before mRNA degradation. J Neurosci 24:10040-10046.

Dröge W, Schipper HM (2007) Oxidative stress and aberrant signaling in aging and cognitive decline. Aging Cell 6:361-370.

Elbashir SM, Lendeckel W, Tuschl T (2001a) RNA interference is mediated by 21- and 22-nucleotide RNAs. Genes Dev 15:188-200.

Elbashir SM, Harborth J, Lendeckel W, Yalcin A, Weber K, Tuschl T (2001b) Duplexes of 21-nucleotide RNAs mediate RNA interference in cultured mammalian cells. Nature 411:494-498.

Epstein AC, Gleadle JM, McNeill LA, Hewitson KS, O’Rourke J, Mole DR, Mukherji M, Metzen E, Wilson MI, Dhanda A, Tian YM, Masson N, Hamilton DL, Jaakkola P, Barstead R, Hodgkin J, Maxwell PH, Pugh CW, Schofield CJ, Ratcliffe PJ (2001) C. elegans EGL-9 and mammalian homologs define a family of dioxygenases that regulate HIF by prolyl hydroxylation. Cell 107:43-54.

Forni GL, Balocco M, Cremonesi L, Abbruzzese G, Parodi RC, Marchese R (2008) Regression of symptoms after selective iron chelation therapy in a case of neurodegeneration with brain iron accumulation. Mov Disord 23:904-907.

Gerald D, Berra E, Frapart YM, Chan DA, Giaccia AJ, Mansuy D, Pouysségur J, Yaniv M, Mechta-Grigoriou F (2004) JunD reduces tumor angiogenesis by protecting cells from oxidative stress. Cell 118:781-794.

Gulyani S, Earley CJ, Camandola S, Maudsley S, Ferré S, Mughal MR, Martin B, Cheng A, Gleichmann M, Jones BC, Allen RP, Mattson MP (2009) Diminished iron concentrations increase adenosine $\mathrm{A}(2 \mathrm{~A})$ receptor levels in mouse striatum and cultured human neuroblastoma cells. Exp Neurol 215:236-242.

Hayashi M (2009) Oxidative stress in developmental brain disorders. Neuropathology 29:1-8.

Huang J, Zhao Q, Mooney SM, Lee FS (2002) Sequence determinants in hypoxia-inducible factor-1alpha for hydroxylation by the prolyl hydroxylases PHD1, PHD2, and PHD3. J Biol Chem 277:39792-39800.

Hwang IK, Yoo KY, Li H, Park OK, Lee CH, Choi JH, Jeong YG, Lee YL, Kim YM, Kwon YG, Won MH (2009) Indole-3-propionic acid attenuates neuronal damage and oxidative stress in the ischemic hippocampus. J Neurosci Res 87:2126-2137.

Imamura T, Kikuchi H, Herraiz MT, Park DY, Mizukami Y, Mino-Kenduson M, Lynch MP, Rueda BR, Benita Y, Xavier RJ, Chung DC (2009) HIFlalpha and HIF-2alpha have divergent roles in colon cancer. Int J Cancer 124:763-771.

Ivan M, Kondo K, Yang H, Kim W, Valiando J, Ohh M, Salic A, Asara JM, Lane WS, Kaelin WG Jr (2001) HIFalpha targeted for VHL-mediated destruction by proline hydroxylation: implications for $\mathrm{O} 2$ sensing. Science 292:464-468.

Jaakkola P, Mole DR, Tian YM, Wilson MI, Gielbert J, Gaskell SJ, Kriegsheim A, Hebestreit HF, Mukherji M, Schofield CJ, Maxwell PH, Pugh CW, Ratcliffe PJ (2001) Targeting of HIF-alpha to the von Hippel-Lindau ubiquitylation complex by O2-regulated prolyl hydroxylation. Science 292:468-472.

Kaelin WG Jr, Ratcliffe PJ (2008) Oxygen sensing by metazoans: the central role of the HIF hydroxylase pathway. Mol Cell 30:393-402.
Kakhlon O, Manning H, Breuer W, Melamed-Book N, Lu C, Cortopassi G, Munnich A, Cabantchik ZI (2008) Cell functions impaired by frataxin deficiency are restored by drug-mediated iron relocation. Blood 112:5219-5227.

Krasnova IN, Cadet JL (2009) Methamphetamine toxicity and messengers of death. Brain Res Rev 60:379-407.

Lee S, Nakamura E, Yang H, Wei W, Linggi MS, Sajan MP, Farese RV, Freeman RS, Carter BD, Kaelin WG Jr, Schlisio S (2005) Neuronal apoptosis linked to EglN3 prolyl hydroxylase and familial pheochromocytoma genes: developmental culling and cancer. Cancer Cell 8:155-167.

Levy OA, Malagelada C, Greene LA (2009) Cell death pathways in Parkinson's disease: proximal triggers, distal effectors, and final steps. Apoptosis 14:478-500.

Li YX, Ding SJ, Xiao L, Guo W, Zhan Q (2008) Desferoxamine preconditioning protects against cerebral ischemia in rats by inducing expressions of hypoxia inducible factor 1 alpha and erythropoietin. Neurosci Bull 24:89-95.

Liot G, Bossy B, Lubitz S, Kushnareva Y, Sejbuk N, Bossy-Wetzel E (2009) Complex II inhibition by $3-\mathrm{NP}$ causes mitochondrial fragmentation and neuronal cell death via an NMDA- and ROS-dependent pathway. Cell Death Differ 16:899-909.

Lomb DJ, Desouza LA, Franklin JL, Freeman RS (2009) Prolyl hydroxylase inhibitors depend on extracellular glucose and HIF-2\{alpha\} to inhibit cell death caused by NGF deprivation: evidence that HIF-2 \{alpha\} has a role in NGF-promoted survival of sympathetic neurons. Mol Pharmacol 75:1198-1209.

Maccioni RB, Rojo LE, Fernández JA, Kuljis RO (2009) The role of neuroimmunomodulation in Alzheimer's disease. Ann N Y Acad Sci 1153:240-246.

Mastrogiannaki M, Matak P, Keith B, Simon MC, Vaulont S, Peyssonnaux C (2009) HIF-2alpha, but not HIF-1alpha, promotes iron absorption in mice. J Clin Invest 119:1159-1166.

Mikhaylova O, Ignacak ML, Barankiewicz TJ, Harbaugh SV, Yi Y, Maxwell PH, Schneider M, Van Geyte K, Carmeliet P, Revelo MP, Wyder M, Greis KD, Meller J, Czyzyk-Krzeska MF (2008) The von Hippel-Lindau tumor suppressor protein and Egl-9-type proline hydroxylases regulate the large subunit of RNA polymerase II in response to oxidative stress. Mol Cell Biol 28:2701-2717.

Mosmann T (1983) Rapid colorimetric assay for cellular growth and survival: application to proliferation and cytotoxicity assays. J Immunol Methods 65:55-63.

Nanduri J, Wang N, Yuan G, Khan SA, Souvannakitti D, Peng YJ, Kumar GK, Garcia JA, Prabhakar NR (2009) Intermittent hypoxia degrades HIF2alpha via calpains resulting in oxidative stress: implications for recurrent apnea-induced morbidities. Proc Natl Acad Sci U S A 106:1199-1204.

O'Reilly SM, Leonard MO, Kieran N, Comerford KM, Cummins E, Pouliot M, Lee SB, Taylor CT (2006) Hypoxia induces epithelial amphiregulin gene expression in a CREB-dependent manner. Am J Physiol Cell Physiol 290:C592-C600.

Petri S, Calingasan NY, Alsaied OA, Wille E, Kiaei M, Friedman JE, Baranova O, Chavez JC, Beal MF (2007) The lipophilic metal chelators DP-109 and DP-460 are neuroprotective in a transgenic mouse model of amyotrophic lateral sclerosis. J Neurochem 102:991-1000.

Ratan RR, Murphy TH, Baraban JM (1994) Oxidative stress induces apoptosis in embryonic cortical neurons. J Neurochem 62:376-379.

Ratan RR, Ryu H, Lee J, Mwidau A, Neve RL (2002) In vitro model of oxidative stress in cortical neurons. Methods Enzymol 352:183-190.

Ratan RR, Siddiq A, Aminova L, Langley B, McConoughey S, Karpisheva K, Lee HH, Carmichael T, Kornblum H, Coppola G, Geschwind DH, Hoke A, Smirnova N, Rink C, Roy S, Sen C, Beattie MS, Hart RP, Grumet M, Sun D et al. (2008) Small molecule activation of adaptive gene expression: tilorone or its analogs are novel potent activators of hypoxia inducible factor-1 that provide prophylaxis against stroke and spinal cord injury. Ann N Y Acad Sci 1147:383-394.

Rogers JT, Bush AI, Cho HH, Smith DH, Thomson AM, Friedlich AL, Lahiri DK, Leedman PJ, Huang X, Cahill CM (2008) Iron and the translation of the amyloid precursor protein (APP) and ferritin mRNAs: riboregulation against neural oxidative damage in Alzheimer's disease. Biochem Soc Trans 36:1282-1287.

Scortegagna M, Ding K, Zhang Q, Oktay Y, Bennett MJ, Bennett M, Shelton JM, Richardson JA, Moe O, Garcia JA (2005) HIF-2alpha regulates mu- 
rine hematopoietic development in an erythropoietin-dependent manner. Blood 105:3133-3140.

Semenza GL (2000) Expression of hypoxia-inducible factor 1: mechanisms and consequences. Biochem Pharmacol 59:47-53.

Semenza GL, Roth PH, Fang HM, Wang GL (1994) Transcriptional regulation of genes encoding glycolytic enzymes by hypoxia-inducible factor 1 . J Biol Chem 269:23757-23763.

Shohet RV, Garcia JA (2007) Keeping the engine primed: HIF factors as key regulators of cardiac metabolism and angiogenesis during ischemia. J Mol Med 85:1309-1315.

Shokolenko I, Venediktova N, Bochkareva A, Wilson GL, Alexeyev MF (2009) Oxidative stress induces degradation of mitochondrial DNA. Nucleic Acids Res 37:2539-2548.

Siddiq A, Ayoub IA, Chavez JC, Aminova L, Shah S, LaManna JC, Patton SM, Connor JR, Cherny RA, Volitakis I, Bush AI, Langsetmo I, Seeley T, Gunzler V, Ratan RR (2005) Hypoxia-inducible factor prolyl 4-hydroxylase inhibition. A target for neuroprotection in the central nervous system. J Biol Chem 280:41732-41743.

Siddiq A, Aminova LR, Ratan RR (2007) Hypoxia inducible factor prolyl 4-hydroxylase enzymes: center stage in the battle against hypoxia, metabolic compromise and oxidative stress. Neurochem Res 32:931-946.

Siddiq A, Aminova LR, Ratan RR (2008) Prolyl 4-hydroxylase activityresponsive transcription factors: from hydroxylation to gene expression and neuroprotection. Front Biosci 13:2875-2887.

Terni B, Boada J, Portero-Otin M, Pamplona R, Ferrer I (2009) Mitochondrial ATP-synthase in the entorhinal cortex is a target of oxidative stress at stages I/II of Alzheimer's disease pathology. Brain Pathol. Advance online publication. Retrieved June 29, 2009. doi:10.1111/j.1750-3639.2009.00266.

Trimmer PA, Bennett JP Jr (2009) The cybrid model of sporadic Parkinson's disease. Exp Neurol. Advance online publication. Retrieved June 24, 2009. doi:10.1016/j.expneurol.2009.03.016.

Unnikrishnan A, Raffoul JJ, Patel HV, Prychitko TM, Anyangwe N, Meira LB, Friedberg EC, Cabelof DC, Heydari AR (2009) Oxidative stress alters base excision repair pathway and increases apoptotic response in apurinic/apyrimidinic endonuclease $1 /$ redox factor-1 haploinsufficient mice. Free Radic Biol Med 46:1488-1499.

Valera E, Sánchez-Martín FJ, Ferrer-Montiel AV, Messeguer A, Merino JM (2008) NMDA-induced neuroprotection in hippocampal neurons is mediated through the protein kinase A and CREB (cAMP-response elementbinding protein) pathway. Neurochem Int 53:148-154.

Visconti R, Grieco D (2009) New insights on oxidative stress in cancer. Curr Opin Drug Discov Devel 12:240-245.

Wang Y, Branicky R, Stepanyan Z, Carroll M, Guimond MP, Hihi A, Hayes S, McBride K, Hekimi S (2009) The anti-neurodegeneration drug clioquinol inhibits the aging-associated protein CLK-1. J Biol Chem 284:314-323.

Weinberg ED, Miklossy J (2008) Iron withholding: a defense against disease. J Alzheimers Dis 13:451-463.

Whitnall M, Richardson DR (2006) Iron: a new target for pharmacological intervention in neurodegenerative diseases. Semin Pediatr Neurol 13:186-197.

Xu Q, Kanthasamy AG, Reddy MB (2008a) Neuroprotective effect of the natural iron chelator, phytic acid in a cell culture model of Parkinson's disease. Toxicology 245:101-108.

Xu X, Sutak R, Richardson DR (2008b) Iron chelation by clinically relevant anthracyclines: alteration in expression of iron-regulated genes and atypical changes in intracellular iron distribution and trafficking. Mol Pharmacol 73:833-844.

Zaman K, Ryu H, Hall D, O’Donovan K, Lin KI, Miller MP, Marquis JC, Baraban JM, Semenza GL, Ratan RR (1999) Protection from oxidative stress-induced apoptosis in cortical neuronal cultures by iron chelators is associated with enhanced DNA binding of hypoxia-inducible factor-1 and ATF-1/CREB and increased expression of glycolytic enzymes, p21(waf1/cip1), and erythropoietin. J Neurosci 19:9821-9830.

Zimmer M, Ebert BL, Neil C, Brenner K, Papaioannou I, Melas A, Tolliday N, Lamb J, Pantopoulos K, Golub T, Iliopoulos O (2008) Small-molecule inhibitors of HIF-2a translation link its 5'UTR iron-responsive element to oxygen sensing. Mol Cell 32:838-848. 